\title{
Optimal Unemployment Insurance
}

\author{
Hugo A. Hopenhayn; Juan Pablo Nicolini \\ The Journal of Political Economy, Vol. 105, No. 2. (Apr., 1997), pp. 412-438.
}

Stable URL:

http://links.jstor.org/sici?sici=0022-3808\%28199704\%29105\%3A2\%3C412\%3AOUI\%3E2.0.CO\%3B2-H

The Journal of Political Economy is currently published by The University of Chicago Press.

Your use of the JSTOR archive indicates your acceptance of JSTOR's Terms and Conditions of Use, available at

http://www.jstor.org/about/terms.html. JSTOR's Terms and Conditions of Use provides, in part, that unless you have obtained prior permission, you may not download an entire issue of a journal or multiple copies of articles, and you may use content in the JSTOR archive only for your personal, non-commercial use.

Please contact the publisher regarding any further use of this work. Publisher contact information may be obtained at http://www.jstor.org/journals/ucpress.html.

Each copy of any part of a JSTOR transmission must contain the same copyright notice that appears on the screen or printed page of such transmission.

The JSTOR Archive is a trusted digital repository providing for long-term preservation and access to leading academic journals and scholarly literature from around the world. The Archive is supported by libraries, scholarly societies, publishers, and foundations. It is an initiative of JSTOR, a not-for-profit organization with a mission to help the scholarly community take advantage of advances in technology. For more information regarding JSTOR, please contact support@ jstor.org. 


\title{
Optimal Unemployment Insurance
}

\author{
Hugo A. Hopenhayn
}

University of Rochester and Universitat Pompeu Fabra

\section{Juan Pablo Nicolini}

Universidad Torcuato di Tella and Universitat Pompeu Fabra

\begin{abstract}
This paper considers the design of an optimal unemployment insurance system. The problem is modeled as a repeated principalagent problem involving a risk-averse agent-the unemployed worker-and a risk-neutral principal, which cannot monitor the agent's search effort. The optimal long-term contract subject to the associated incentive constraints is characterized. This contract involves a replacement ratio that decreases throughout the unemployment spell and a wage tax after reemployment that, under some mild regularity conditions, increases with the length of the unemployment spell. Some numerical results are presented that suggest that the gains from switching to this optimal unemployment insurance scheme could be quite large. The performance of this optimal contract is also compared to alternative liquidity provision mechanisms.
\end{abstract}

\section{Introduction}

An important ingredient of social welfare policies in developed economies is the unemployment insurance program. For the Euro-

We are grateful to Peter Diamond, Jonathan Gruber, and Jean-Jacques Laffont for many useful comments. We also wish to thank seminar participants at the University of Chicago, University of Iowa, the Massachusetts Institute of Technology-Harvard seminar in public finance, the Federal Reserve Bank of Minneapolis, and the National Bureau of Economic Research Summer Institute. We acknowledge John Knowles for his helpful suggestions in editing the paper. Hopenhayn gratefully acknowledges financial support from the National Science Foundation. 
pean Community countries, public expenditures on unemployment insurance averaged around 2 percent of gross national product for the second half of the $1980 \mathrm{~s}$, ranging from a low 0.23 percent for Luxembourg to a high 3.4 percent for the Netherlands (Melguizo and Lopez 1991). For Canada, Japan, and the United States, these numbers were 1.6 percent, 0.4 percent, and 0.4 percent, respectively, for the year 1990 (Green and Ridell 1993).

In spite of their widespread use, unemployment insurance programs have been widely criticized because of the perverse effects they have on the incentives for reemployment. In fact, many of the current programs have been designed with the aim of reducing these distortions. For instance, the benefit received may be a small fraction of the previous wage, and a certain number of previous periods of employment may be required to qualify for benefits. In addition, benefits usually expire after a relatively short number of periods. The purpose of this paper is to examine more formally the problem of optimal design of an unemployment insurance program and to provide some estimates of the potential gains that could result from its adoption.

We model the incentive problem created by unemployment insurance as a standard repeated moral hazard problem in a multiperiod setup. The key feature of the environment is that the probability of finding a new job depends on the search effort made by the agent, which is not observed by the principal. The unemployment insurance contract specifies a time sequence of transfers between the principal (e.g., government) and the agent (unemployed worker), conditional on the length of the unemployment spell. This contract minimizes the expected discounted value of these net transfersthe budget-subject to providing the agent with a prespecified welfare level.

In their seminal work on unemployment insurance, Shavell and Weiss (1979) established that in order to provide the appropriate incentives to search, benefits must decrease monotonically throughout the unemployment spell. A novel feature of the contract we study here is that it considers as a policy instrument, together with the sequence of benefits paid to the unemployed worker, a wage tax after reemployment. We establish that the result obtained by Shavell and Weiss remains valid: the optimal unemployment insurance contract involves a decreasing sequence of insurance payments to the worker while unemployed, followed by a constant tax rate after reemployment. We also show that, under mild regularity conditions, this tax increases with the length of the unemployment spell. The transfers to the unemployed worker increase with the initial level of expected utility offered by the insurance contract, which can thus be 
parameterized by the initial replacement ratio. The results above hold for all initial replacement ratios and, in particular, for the one that balances the principal's budget.

The logic behind our results is quite transparent: To provide intertemporal incentives, the contract must punish workers for continued unemployment by reducing their claims to future consumption. Aside from further incentive considerations, if agents are risk-averse, consumption should be reduced at all possible future states of nature, namely, those states in which the agent remains unemployed and those in which the agent becomes employed. The former explains why transfers decrease with the length of unemployment and the latter why taxes on wages should increase, provided that negative incentive effects are not too strong.

To evaluate the advantages of the optimal mechanism, we provide estimates of the cost reduction obtained by shifting from the current unemployment insurance scheme to the optimal one, holding the ex ante utility of the unemployed agent constant. The gains are particularly large (about 30 percent) for an agent with no wealth or other source of income and with no access to borrowing. In contrast, the gains from shifting to the optimal scheme with no taxation (as the one considered by Shavell and Weiss) are very moderate, falling short of 5 percent. Our results suggest that to a large extent the relative advantage of the optimal unemployment scheme derives from smoothing the unemployed worker's consumption relative to the current scheme. ${ }^{1}$ To evaluate this hypothesis, we provide similar calculations for agents with an initial wealth endowment that allows them to substitute for the smoothing provided by the optimal contract. As this wealth endowment increases, the gains from the optimal insurance contract decrease, approaching the values obtained for the Shavell and Weiss contract.

We model the optimal contract problem as a dynamic programming problem, following the work of Spear and Srivastava (1987) and Phelan and Townsend (1991). As in the latter paper, we emphasize the moral hazard problem that arises from the difficulties in monitoring the agent's effort, in our case search effort. Another interesting source of informational asymmetry arises when the principal cannot observe the job offers received by the agent. This is ruled out in our paper by assuming that all potential job offers are identical and permanent. In Shavell and Weiss's paper, the agent's search

\footnotetext{
${ }^{1}$ With some variations across states, the current system provides workers with a replacement ratio of approximately 60 percent for a maximum of 6 months. Gruber (1996) shows that for the U.S. economy, consumption decreases when unemployed workers cease to be eligible for unemployment insurance benefits.
} 
effort determines the conditional distribution from which a permanent wage offer is privately sampled. The principal has the double disadvantage of neither being able to monitor the search effort nor imposing a reservation wage rule for job acceptance.

Following Hansen and Imrohoroglu (1992), Atkeson and Lucas (1995) consider the optimal contract in a pure adverse-selection setup with temporary (one-period) job offers. Their paper focuses on the role of asymmetric information as a source of incomplete insurance and its implications for the evolution of income distribution. Usami (1983) considers a model with moral hazard and two effort levels, where the probability of employment conditional on search may depend on the employment history. He establishes that benefits should be nonincreasing while the worker remains unemployed and that the worker's compensation should be nondecreasing throughout the period of employment. In a recent paper, Wang and Williamson (1996) present a calibrated version of a model of this type and perform welfare comparisons similar to the ones discussed above.

The paper proceeds as follows. In Section II we describe the model and state the main theoretical results. Section III provides the estimates of welfare gains from the optimal unemployment insurance contract. Section IV contains some concluding remarks.

\section{The Model}

\section{A. The Environment}

In this section we characterize the optimal unemployment insurance contract between a risk-averse agent and a risk-neutral principal. The preferences of the agent are

$$
E \sum_{t=0}^{\infty} \beta^{t}\left[u\left(c_{t}\right)-a_{t}\right],
$$

where $c_{t}$ and $a_{t}$ are consumption and search effort at time $t, \beta<1$ is a discount factor, and $E$ is the expectation operator. Consumption takes values on $\mathbb{R}_{+}$, and effort can take any value on a closed interval $A$ containing zero. The function $u$ is increasing and concave. ${ }^{2}$

The probability of finding a job $p_{t}$ is a function of the search effort

\footnotetext{
${ }^{2}$ Notice that when we change units of measurement, $a_{t}$ can be replaced by a convex function $v\left(a_{t}\right)$. Our assumptions are thus fairly standard ones, namely concavity, additive time separability, and additive separability between consumption and leisure.
} 
$a_{t}$ of the unemployed worker given by

$$
p_{t}=p\left(a_{t}\right)
$$

where $p$ is increasing, strictly concave, and twice differentiable and satisfies standard Inada conditions so that search effort is interior.

Assume that the worker has no other source of income and that the principal can directly control his or her consumption. Provided that the latter condition holds, the first assumption arises without loss of generality if the alternative sources of income are independent of the search effort and employment status of the agent or can be monitored at no cost by the principal. The assumption of direct control of the agent's consumption stream precludes the occurrence of trades such as borrowing and lending without knowledge of the principal. This assumption is quite typical in the repeated agency literature and provides an upper bound on what can be achieved through an optimal contract.

Assume that all jobs are identical, offering a permanent (and constant) wage $w$ over time. These two assumptions are to some extent a matter of convenience. The theoretical results presented below generalize to the case of repeated unemployment spells in which jobs terminate exogenously. However, the extensions to the case of heterogeneous wage offers are not immediate. Shavell and Weiss consider the case in which wage offers cannot be monitored by the principal, obtaining, for a more restricted set of contracts, properties that correspond to some of our results. If wage offers could be monitored by the principal, this additional information would most certainly be used to condition payments in the optimal contract. We abstract from these considerations.

For notational convenience we have not considered explicitly the disutility of effort when the agent is employed. Though this can affect the quantitative results, it is a constant term in the utility of an employed worker and has no consequence on the qualitative properties of the optimal contract derived below. In the numerical section we present some results with costly work effort.

\section{B. The Contract}

At time 0 a risk-neutral principal offers a contract to the risk-averse unemployed agent. As usual, the contract specifies net transfers to the agent and a recommended action $a_{t}$ as a function of the realized history. Let 0 denote the state of unemployment and 1 the state of employment. History up to period $t$ is denoted by $\mathbf{h}_{t}$, a vector of $t-1$ states $\left\{s_{j}\right\}_{j<t}$ containing all zeros if the agent is still unemployed at the beginning of period $t$ or $t^{\prime}-1$ zeros followed by $t-t^{\prime}$ ones 
if the agent received a job offer at the end of period $t<t$. The contract is a function $\tau: \mathbf{h}_{t} \rightarrow\left\{a_{t}, z_{t}\right\}$, where $a_{t}$ is the recommended search effort (relevant only if the worker is unemployed) and $z_{t}$ a net transfer from the principal to the agent. Associated with each contract is an expected discounted utility to the agent $V_{0}(\tau)$ and a cost, measured by the expected discounted value of net transfers to the agent, $C_{0}(\tau)$. These values assume that the agent responds to the contract rationally maximizing (1) by choosing the search effort $\hat{a}_{t}$. As usual, we assume that the principal discounts future flows at the same rate as the agent. Given a level of initial value $V$ for the agent, the optimal contract minimizes $C_{0}(\tau)$ subject to $V_{0}(\tau)=V$.

Notice that we assume that the principal has the ability to commit to a transfer policy. Time-consistency considerations are not likely to arise in this context unless a worker remains unemployed for many periods or starts with a very low coverage. In any case, if we interpret the contract as the set of rules imposed by the insurance agency, reputational considerations would keep the principal from renegotiating the terms of the unemployment insurance with a single agent even though a point were reached at which such renegotiation could be mutually beneficial.

\section{The Full-Information Case}

If the unemployed worker's search effort were observable, the problem would be purely one of efficient risk sharing in which the principal would bear all the risk. The optimal program would then give the agent a constant consumption $c$ per period and prescribe a constant effort level $a^{*}$ that maximizes the expected discounted value of wages (valued at the marginal utility of consumption for the worker) net of the cost of search effort, that is,

$$
a^{*}=\underset{a}{\operatorname{argmax}} p(a) \sum_{t=0}^{\infty} \delta^{t}[1-p(a)]^{t}\left[\frac{\delta u^{\prime}(c) w}{1-\delta}-a\right] .
$$

It is easy to verify that $a^{*}$ is a decreasing function of $c$ and thus higher levels of consumption represent a higher utility for the worker and a higher cost to the principal. The transfer $z_{t}$ from the principal to the worker would be equal to his consumption $c$ while unemployed and $c-w$ after employment.

\section{Unobservable Search Effort}

The optimal contract specified above depends crucially on the observability of the effort level. It is clear that, as effort enters negatively 
in his utility function, the agent has no incentive to search, since consumption does not depend on the state of nature. In fact, a widespread critique of existing unemployment insurance schemes is that they strongly reduce the incentives to look for a job. It seems quite natural then to study the optimal contract problem assuming that the effort level is not observable by the principal.

Following recent developments in the literature of repeated moral hazard (see Spear and Srivastava 1987; Phelan and Townsend 1991), we write the optimal contract problem in recursive form. Suppose that the contract offers at time 0 an expected discounted utility to the worker equal to $V$. The contract specifies current consumption $c$ and effort $a$ and promised levels of future expected discounted utility, all contingent on the state of nature. Let $V^{e}$ be the expected discounted utility at the beginning of period 1 that the contract assigns to an unemployed worker who finds a job at the end of period 0 , and $V^{u}$ the corresponding expected discounted utility if he does not find a job. Since $V$ is the expected discounted utility offered by the contract to the worker at the beginning of period 0 , it follows that

$$
V=u(c)-a+\beta\left\{p(a) V^{e}+[1-p(a)] V^{u}\right\} .
$$

Given that the search effort is not observed by the principal, we must include the restriction that the agent optimally chooses the effort level $a$ prescribed by the contract. The following incentivecompatibility constraint is thus needed:

$$
a \in \underset{\hat{a} \in A}{\operatorname{argmax}} U(c)-\hat{a}+\beta\left\{p(\hat{a}) V^{e}+[1-p(\hat{a})] V^{u}\right\} .
$$

The solution to this problem depends on the sign of $V^{e}-V^{u}$. It is easy to see that the optimal effort level $a$ will be strictly greater than zero if and only if $V^{e}>V^{u}$. Since $p$ is strictly concave, a necessary and sufficient condition for $a$ to be the optimal search effort chosen by the worker is

$$
\beta p^{\prime}(a)\left(V^{e}-V^{u}\right)=1 .
$$

We now specify the recursive problem that defines the optimal contract. First consider the structure of the optimal contract starting at the time the worker becomes employed. Let $V^{e}$ represent the expected discounted utility the worker has at this specific node. Given that at this point there is no further incentive problem between the principal and the agent, it is optimal to give the agent a constant level of consumption $c^{e}$ defined implicitly by $V^{e}=u\left(c^{e}\right) /(1-\beta) .^{3}$

\footnotetext{
${ }^{3}$ Note that if employment required a constant effort level $e$, then $V^{e}=$ $[u(c) /(1-\beta)]-[e /(1-\beta)]$, which amounts to just subtracting a constant term from the current specification.
} 
The net transfer from the principal to the agent will then be $c^{e}-$ $w$ per period. Let

$$
W\left(V^{e}\right)=\frac{-w+u^{-1}\left[(1-\beta) V^{e}\right]}{1-\beta}
$$

denote the present value of this net transfer that represents the continuation cost of the contract for the principal. Note that if $c^{e}<w$, the principal will levy a tax per period equal to $w-c^{e}$, so that this continuation cost $W\left(V^{e}\right)<0$. It is straightforward to verify that $W$ is strictly decreasing and strictly convex and that

$$
W^{\prime}\left(V^{e}\right)=\frac{1}{u^{\prime}\left(c^{e}\right)} .
$$

Consider now the situation faced by the principal when the agent is unemployed. Let $C(V)$ be the expected discounted cost for the principal associated with the optimal contract when the agent is unemployed with a continuation value $V_{0}=V$. Then $C(V)$ must satisfy the following Bellman equation:

$$
C(V)=\min _{a, c, V^{e}, V^{u}} c+\beta\left\{p(a) W\left(V^{e}\right)+[1-p(a)] C\left(V^{u}\right)\right\}
$$

subject to

$$
u(c)-a+\beta\left\{p(a) V^{e}+[1-p(a)] V^{u}\right\}=V
$$

and

$$
\beta p^{\prime}(a)\left(V^{e}-V^{u}\right)=1 .
$$

Note that restrictions (8) and (9) are not linear. In fact, they generally define a set that is not convex. It thus becomes hard to provide conditions under which the solution to the dynamic programming problem results in a convex cost function $C(V)$. If the cost function is not convex, the solution to the program above can be improved by using lotteries over the control variables. This is a linear programming problem, which can be solved numerically, as shown in Phelan and Townsend.

However, the optimal plan may not involve the use of lotteries, because convexity of the choice set is a sufficient but not necessary condition for convexity of the cost function. There may be a class of problems for which lotteries are never part of the optimal contract. Indeed, in all our numerical computations in Section III, the function $C$ turns out to be convex, making lotteries redundant. Since the objective of this section is to derive some general properties of the 
optimal contracts, we shall focus on the optimal program defined above, disregarding the use of lotteries.

The first-order conditions for the principal's problem are

$$
\begin{gathered}
p^{\prime}(a)\left[W\left(V^{e}\right)-C\left(V^{u}\right)\right]=\eta p^{\prime \prime}(a)\left(V^{e}-V^{u}\right), \\
C^{\prime}\left(V^{u}\right)=\frac{1}{u^{\prime}\left(c^{u}\right)}-\eta \frac{p^{\prime}(a)}{1-p(a)},
\end{gathered}
$$

and

$$
W^{\prime}\left(V^{e}\right)=\frac{1}{u^{\prime}\left(c^{u}\right)}+\eta \frac{p^{\prime}(a)}{p(a)},
$$

where $\eta$ is the multiplier on the incentive-compatibility constraint. The envelope condition is

$$
C^{\prime}(V)=\frac{1}{u^{\prime}\left(c^{u}\right)}=[1-p(a)] C^{\prime}\left(V^{u}\right)+p(a) W^{\prime}\left(V^{e}\right),
$$

where the second equality follows from (11) and (12) above.

\section{E. Analysis}

We now proceed to derive some general properties of the optimal unemployment insurance contract, focusing on how the duration of unemployment affects the net transfers to the worker. Shavell and Weiss established that along an interior solution their optimal contract exhibits decreasing benefits. The following proposition shows that in our setup, with a richer set of policies that allows for taxation of wages, their result still holds.

Proposition 1. The unemployment benefit is decreasing over time while the worker remains unemployed. Additionally, if $C$ is convex, then $V^{u}<V$.

Proof. From (11) and (12) we obtain

$$
W^{\prime}\left(V^{e}\right)-C^{\prime}\left(V^{u}\right)=\eta p^{\prime}(a)\left[\frac{1}{1-p(a)}+\frac{1}{p(a)}\right] .
$$

By the lemma proved in the Appendix, $\eta$ is positive, and thus $W^{\prime}\left(V^{e}\right)>C^{\prime}\left(V^{u}\right)$. From equation (13) it follows that

$$
W^{\prime}\left(V^{e}\right)>C^{\prime}(V)>C^{\prime}\left(V^{u}\right)
$$

which, again with the envelope condition (13) and the concavity of the utility function, implies that the consumption of the unemployed agent must decrease over time. If $C$ is a convex function, then inequality (14) directly implies that $V^{u}<V$. Q.E.D. 
We turn now to the characterization of the tax rate. Recall that under the Shavell and Weiss unemployment contract there is no taxation of wages, so $V_{t}^{e}=u(w) /(1-\beta)$ for every period. Proposition 2 shows that under the optimal contract $V_{t}^{e}$ cannot remain constant forever. This means that the tax plays a role that is not being exploited in current unemployment insurance programs.

Proposition 2. The wage tax is not independent of the unemployment history.

Proof. See the Appendix.

A stronger result may be conjectured; namely, as benefits decrease with the length of the unemployment spell, taxes should increase. The intuition behind the conjecture is the following one. To provide intertemporal incentives, the contract must punish workers for continued unemployment by reducing their claims to future consumption. Aside from further incentive considerations, if agents are riskaverse, consumption should be reduced at all possible future states of nature, namely, those states in which the agent remains unemployed and those in which the agent becomes employed. The former explains why transfers decrease with the length of unemployment and the latter why taxes on wages should increase, provided that negative incentive effects are not too strong. The following proposition provides conditions under which the permanent income effects dominate over this negative incentive effect.

Proposition 3. Under either of the following two conditions, if $C$ is convex, then the tax levied on the worker will increase with the length of the previous unemployment spell: $(a)\left\{-p^{\prime \prime}(a)[1\right.$ - $p(a)] p(a)\} / p^{\prime}(a)^{3}$ is increasing in $a ;(b)-p^{\prime \prime}(a) / p^{\prime}(a)^{2}$ is increasing in $a$.

Proof. See the Appendix.

Condition $b$ has an intuitive interpretation. Differentiating equation (9), we get

$$
\frac{-p^{\prime}(a)^{2} \beta}{p^{\prime \prime}(a)}=\frac{d a}{d\left(V^{e}-V^{u}\right)},
$$

the response of the effort level to increased incentives. Condition $b$ states that this response is decreasing as the effort level increases, making it increasingly costly to provide incentives for search effort. The marginal cost for the principal of increasing the effort is given by the right-hand side of (10). Thus, if $p^{\prime \prime}$ were to decrease significantly with effort in absolute value, the marginal cost of increasing effort would be reduced, and it may then be optimal for the principal to increase the effort. If this effect is sufficiently strong, it may be necessary to reduce the tax in order to give the right incentives. 
Note that the conditions given in proposition 3 are sufficient but not necessary for $V^{e}$ to decrease. It is possible that as $V$ falls, even if the effort increases, $V^{e}$ may fall too, although by a smaller amount than the reduction in $V$. Indeed it can be shown that

$$
\frac{d V^{e}}{d V} \stackrel{s}{=} \frac{d a}{d V}+1
$$

So for $V^{e}$ to increase as $V$ falls, the increase in $a$ must exceed the reduction in the continuation value $V$ as the agent continues unemployed.

The unemployment insurance contract is parameterized by $V$, the level of welfare provided to the unemployed agent. A natural question is how this level $V$ affects the characteristics of the contract. Without strong wealth effects on incentives, one might expect that all net transfers should increase with $V$. The following proposition and corollary establish that under the conditions discussed above, the optimal insurance contract will indeed have this property.

Proposition 4. Suppose that $-p^{\prime \prime}(a) / p^{\prime}(a)^{2}$ is increasing in $a$ and $C$ is convex. Then $V^{u}$ will be an increasing function of the initial value $V$.

Proof. See the Appendix.

CoROLLARY. If $-p^{\prime \prime}(a) / p^{\prime}(a)^{2}$ is increasing in $a$ and $C$ is convex, all net transfers will increase with the initial value $V$.

Proof. Follows immediately by repeatedly applying propositions 3 and 4.

The results from proposition 2 show that the tax will be used in the optimal contract. Thus it must improve on the environment in which no tax is allowed. Proposition 3 provides sufficient conditions so that the tax increases with the length of the unemployment spell. In the following section we calibrate and solve the model to estimate the potential gains of introducing the optimal unemployment insurance mechanism.

\section{Quantitative Analysis}

In this section we solve numerically a parameterized version of the model and provide some rough estimates of the potential advantage of the optimal unemployment insurance contract described above. In subsection $A$ we discuss a procedure to assign parameter values based on recent estimates of hazard rates for several states in the United States. We then solve the optimal unemployment insurance contract with and without taxation and compare the cost of providing a fixed level of welfare equal to current U.S. unemployment in- 
surance across the different regimes. Though we make use of fairly strong functional form assumptions and the calibration is fairly rough, the results are suggestive about the orders of magnitude of these potential gains.

\section{A. Calibration}

This subsection describes a method to assign parameter values to the model. These parameters involve those corresponding to the utility function $u$, the hazard function $p$, and the discount factor $\beta$. Given that we use estimates of weekly hazard rates from Meyer (1990), our time period is 1 week. Correspondingly, we set $b=0.999$, representing a yearly discount factor of 0.95 .

We assume that the utility function has the form $u(c)=$ $c^{1-\sigma} /(1-\sigma)$. We set the value of $\sigma$ to $1 / 2$, giving an intermediate degree of risk aversion. This number may seem small relative to those used in the macro literature, which are generally above one. However, it should be taken into account that we are using weekly data for our calibration exercise, and the elasticity of substitution on weekly consumption is most probably larger than that corresponding to quarterly consumption. A higher value of $\sigma$ implies a stronger degree of risk aversion, making more relevant the insurance mechanism discussed in the paper. For comparison, subsection $B 1$ provides results for higher $\sigma$.

For the hazard function, we use an exponential distribution $p(a)=1-e^{-r a}$ with parameter $r$, multiplicative in the search effort. It is easy to check that this function satisfies the assumptions in proposition 3, so the optimal tax will increase with the length of unemployment.

To assign a value to this parameter $r$, we proceed as follows. Consider the situation of an unemployed worker after benefits have expired. For the benchmark case we assume that the worker has no other source of income or borrowing and lending, so his consumption is zero while unemployed and equal to $w$ once employed. ${ }^{4}$ We normalize this wage to 100 . The optimal search problem for this worker is a stationary one. The value obtained once employed is $V^{e}$ $=u(100) /(1-\beta)$. Let $V^{u}$ represent the value while unemployed. The dynamic programming equation for the optimal search problem is then given by

$$
V^{u}=\max _{a}\left[u(0)-a+\beta V^{u}+\beta p(a)\left(V^{e}-V^{u}\right)\right] .
$$

${ }^{4}$ This assumption is relaxed later to analyze the sensitivity of our results to the initial wealth position of the agent. 
The stationary value $a^{*}$ for the search effort is determined by the first-order condition

$$
\beta p^{\prime}\left(a^{*}\right)\left(V^{e}-V^{u}\right)=1 .
$$

The solution to this problem implies a stationary hazard rate $p\left(a^{*}\right)$. For the (large) range of values considered, this hazard rate is an increasing function of the parameter $r$. Consequently, we chose this parameter to match the corresponding empirical hazard rates.

Meyer (1990) presents estimates of hazard rates for reemployment of unemployed workers as a function of the number of weeks of residual unemployment insurance. The data set used contained 4,628 observations of which 3,365 were used and involves males from 12 states during the period 1978-83. The initial length of benefits in his sample has a mean of 34 weeks, and the mean replacement rate (unemployment benefits/ previous wage) is 66 percent. ${ }^{5}$ For this sample, the Kaplan-Meier estimate for the hazard rate at the time of expiration of benefits is 10 percent. Accounting for heterogeneity in his estimates, Meyer shows that this number may underestimate considerably the hazard rate corresponding to an average agent in the sample. For our benchmark computations we choose $r$ to match the 10 percent hazard rate. Subsection $B 1$ provides some results for higher hazard rates. The results obtained are qualitatively similar to the ones obtained for the benchmark case.

\section{Cost and Value of the Current Insurance System}

Given the parameters assigned above, we can solve for the expected cost of the current unemployment insurance system and the initial value it provides to the unemployed agent. This value will later be used to compute the cost of providing equal expected utility with the optimal contract.

The current insurance system is represented by a contract that pays a fixed amount to the unemployed worker for a maximum number of periods $T$ and no tax or transfer when employed. The problem faced by the unemployed worker has a nonstationary solution. However, it is stationary and identical to the case in which there is no insurance from time $T$ onward. We can thus solve the model backward from time $T$ to time 0 . For period $T$ the solution was derived above. Let $V_{0}^{u}$ denote the corresponding value function for an

\footnotetext{
${ }^{5}$ In our model, with only one unemployment spell, there is no preunemployment wage. As we do not have information regarding reemployment wages, we assume that they are identical to our constant wage $w$.
} 
unemployed worker. At $T-1$, the problem for the unemployed worker is

$$
V_{-1}^{e}=\max _{a}\left[u(b)-a+\beta V^{u}+\beta p(a)\left(V^{e}-V_{0}^{u}\right)\right] .
$$

Denoting by $a_{-1}$ the solution to this equation, we obtain

$$
V_{-1}^{u}=\left[u(b)-a_{-1}+\beta V^{u}+\beta p\left(a_{-1}\right)\left(V^{e}-V^{u}\right)\right] .
$$

More generally, for $0 \leq t \leq T$, we can define the value $V_{-t}^{u}$ recursively by

$$
V_{-t}^{u}=\max _{a}\left\{u(b)-a+\beta V_{-(t-1)}^{u}+\beta p(a)\left[V^{e}-V_{-(t-1)}^{u}\right]\right\} .
$$

Following this recursion, we can solve for the value functions and effort levels up to the first period of unemployment. It is easy to see that as the agent gets closer to the termination date, the effort will be larger, which is consistent with the increasing trend of the hazard before the termination date in the data. The expected cost of this insurance contract is the expected discounted value of the flow of transfers $b$. The expectation is easily computed by using the hazard rates associated with the optimal effort levels $\left\{a_{-t}\right\}$.

The level of benefits $b$ was chosen to match the data from table 1 in Meyer (1990). According to his calculations, the average benefit received was 66 percent of the average value of the preunemployment wage. As we normalized the real wage to be 100 , we set $b$ equal to 66. Finally, we set the number of periods with benefit $T=26$, which, under normal conditions, is the time limit for benefits in most states in the United States.

\section{B. Numerical Results}

Using the parameter values obtained above, we computed results for two alternative regimes: the optimal contract with and without wage taxes. The latter contract corresponds to the one considered by Shavell and Weiss. Table 1 reports the evolution of the optimal unemployment insurance contract, where the initial expected utility value offered to the worker is the same as the one offered under the current regime at the beginning of the unemployment spell. Column 1 gives the replacement ratio (benefits/wage) under the optimal contract. Note that the replacement ratio decreases over time but at a fairly slow rate; even after 1 year of unemployment it exceeds 90 percent. Column 2 reports the constant consumption flow received by the worker once he finds a job, as a function of the weeks of unemployment. Column 3 reports the implicit tax on 
TABLE 1

OPTIMAL UNEMPLOYMENT INSURANCE

\begin{tabular}{lcccc}
\hline \hline & \multicolumn{3}{c}{ Optimal with TAX } & \\
\cline { 2 - 4 } $\begin{array}{c}\text { WEEKS OF } \\
\text { UNEMPLOYMENT }\end{array}$ & $\begin{array}{c}\text { Replacement } \\
\text { Ratio } \\
(1)\end{array}$ & $\begin{array}{c}C \text { Emp } \\
(2)\end{array}$ & $\begin{array}{c}\text { Tax }(\%) \\
(3)\end{array}$ & $\begin{array}{c}\text { Optimal with No TAX: } \\
\text { RePLACEMENT RATIO } \\
(4)\end{array}$ \\
\hline 1 & 99.0 & 100.5 & -.5 & 85.8 \\
2 & 98.9 & 100.4 & -.4 & 80.8 \\
3 & 98.8 & 100.3 & -.3 & 76.3 \\
4 & 98.7 & 100.2 & -.2 & 72.1 \\
5 & 98.6 & 100.1 & -.1 & 68.2 \\
6 & 98.5 & 100.0 & .0 & 64.7 \\
7 & 98.4 & 99.9 & .1 & 61.4 \\
8 & 98.3 & 99.8 & .2 & 58.4 \\
12 & 97.9 & 99.4 & .6 & 48.2 \\
16 & 97.5 & 99.0 & 1.0 & 40.5 \\
26 & 96.5 & 98.0 & 2.0 & 27.7 \\
52 & 94.0 & 95.5 & 4.5 & 13.4 \\
\hline
\end{tabular}

wages. As predicted by the theory, the tax is used in the optimal contract, and it increases with the length of unemployment. Note also that for the first 5 weeks the tax is negative, which means that unemployed workers receive a permanent subsidy if they find a job quickly.

Column 4 of table 1 reports the replacement ratio or benefits for the optimal contract if the principal is constrained not to use the tax as a policy instrument, as in Shavell and Weiss. Note that in this case the replacement ratio also decreases over time, but in a much more dramatic way. In particular, after 6 weeks of unemployment, the benefit is smaller than the one offered by the current contract. The intuition for the result is straightforward. The contract must punish unemployed workers who do not find a job in order to give them the right incentives to put effort in the search process. Since taxes are bound to be zero, the punishment must be incurred through lower benefits only, which explains the sharp decline. In contrast, by taxing future wages, the unrestricted optimal contract provides a much smoother consumption profile.

In order to illustrate the potential gains of using the tax in the optimal contract, figures 1 and 2 plot the expected cost to the principal of providing a range of expected utility values to the agent, with and without the tax. Figure 1 reports the total expected cost in each case, measured in units of consumption. In figure 2, we report the percentage savings created by the introduction of the tax. The level of utility is measured in weekly flow equivalent consumption ranging 


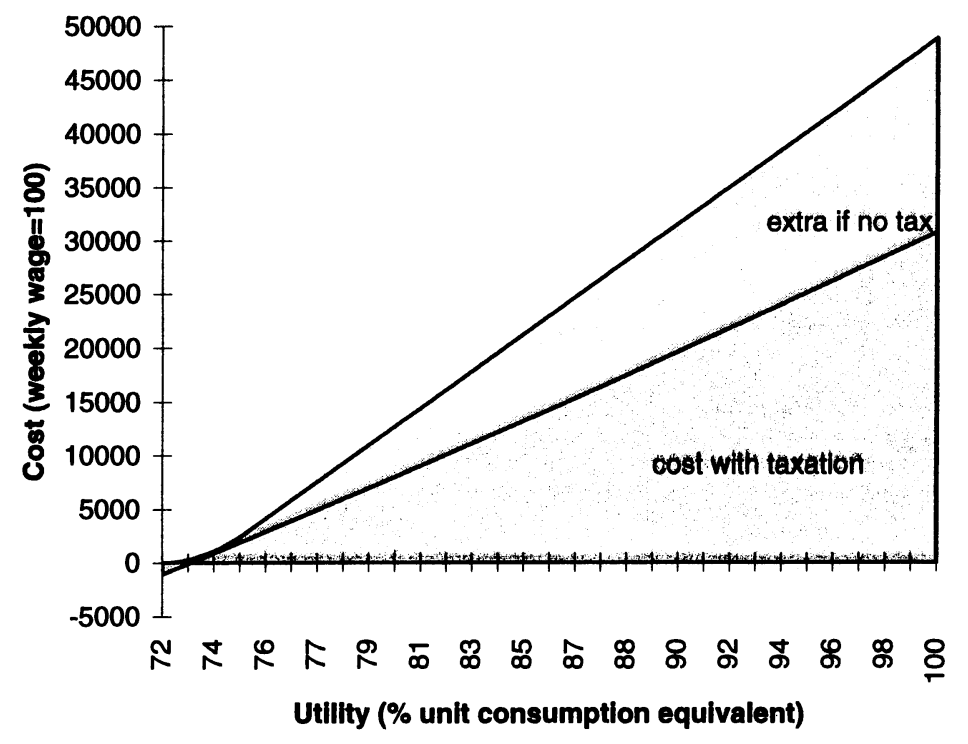

Fig. 1.-Cost of insurance

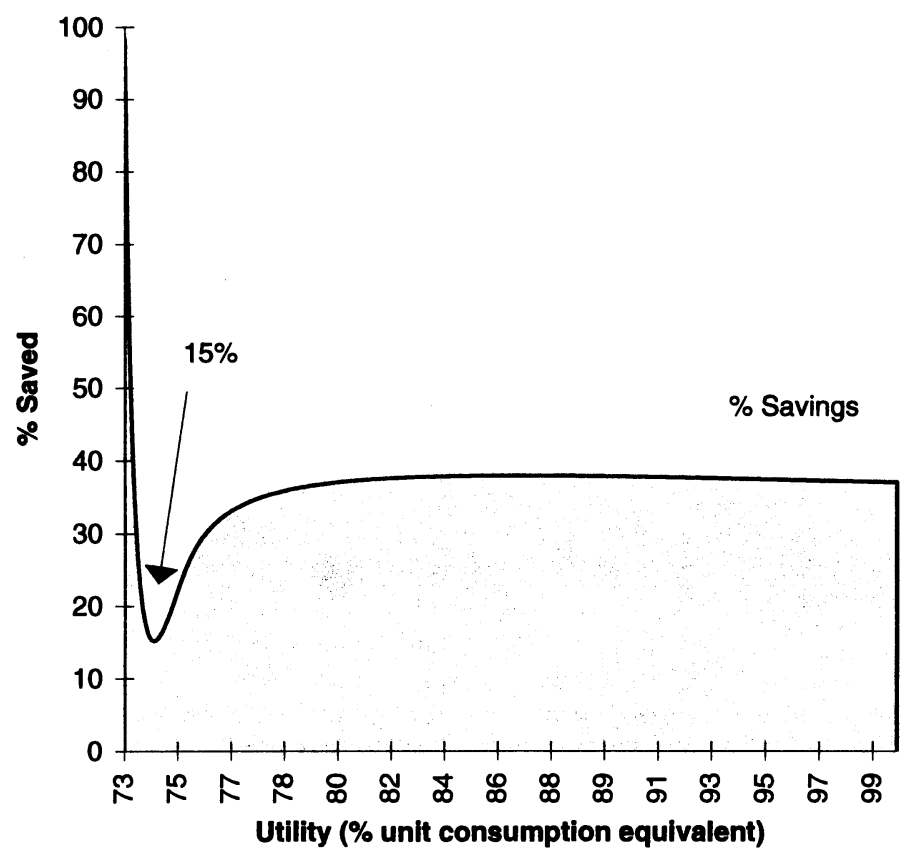

FIG. 2.-Savings if tax included 
from 72 percent to 100 percent of the weekly wage. The former corresponds to a level of welfare equivalent to receiving a constant wage of 72 per period, and the latter corresponds to the welfare of a permanently employed worker. ${ }^{6}$

There is a substantial difference between the cost of the optimal contract with and without taxation, with a minimum percentage savings of 15 percent for the first. Notice also that the gains from this contract are not monotonic. The percentage gain is very large at levels of utility for the worker close to autarky. This reflects the fact that without taxation, autarky puts a lower bound to the utility that the agent can get from the contract. At levels close to autarky, there are no good punishments left to provide incentives to the worker, and thus effort is low. In contrast, the ability to tax wage income allows the principal to lower the discounted utility of the agent below autarky, under the assumption that such a contract can be enforced.

To compute the cost savings that can be derived from either of these contracts, we calculated the expected cost for each of them, assuming that the initial welfare of the agent is held constant at the value corresponding to the current system, calculated according to the method described above. These costs were then compared to the expected cost of the current regime. The savings, reported in column 1 of table 3 below, are quite remarkable (almost 30 percent) for the optimal contract described in this paper, whereas the savings for the optimal contract with no tax are more moderate (slightly less than 8 percent).

Where do these large savings come from? One may be tempted to conjecture that the optimal contract involves fine-tuning the incentives provided to the agent and that this could partly explain these savings. Such a conjecture is not warranted. Figure 3 plots the probability of remaining unemployed as a function of the weeks of unemployment under the current unemployment insurance regime and the two optimal ones. There is very little difference between the curves, reflecting similar values for the agent's effort under these alternative regimes. The large cost savings must then come from an alternative source, which we now discuss. ${ }^{7}$

\footnotetext{
${ }^{6}$ Note that throughout the whole range the cost of the program increases with the welfare of the unemployed worker, tracing in that way a Pareto frontier between the utility of the principal and the agent. This implies that there are no gains from renegotiating the contract.

${ }^{7}$ The computations in Wang and Williamson (1996) also show large benefits from an optimal unemployment insurance program. As in our model, the optimal contract has a very small effect on the duration of unemployment. It does, however, reduce the incidence of unemployment.
} 


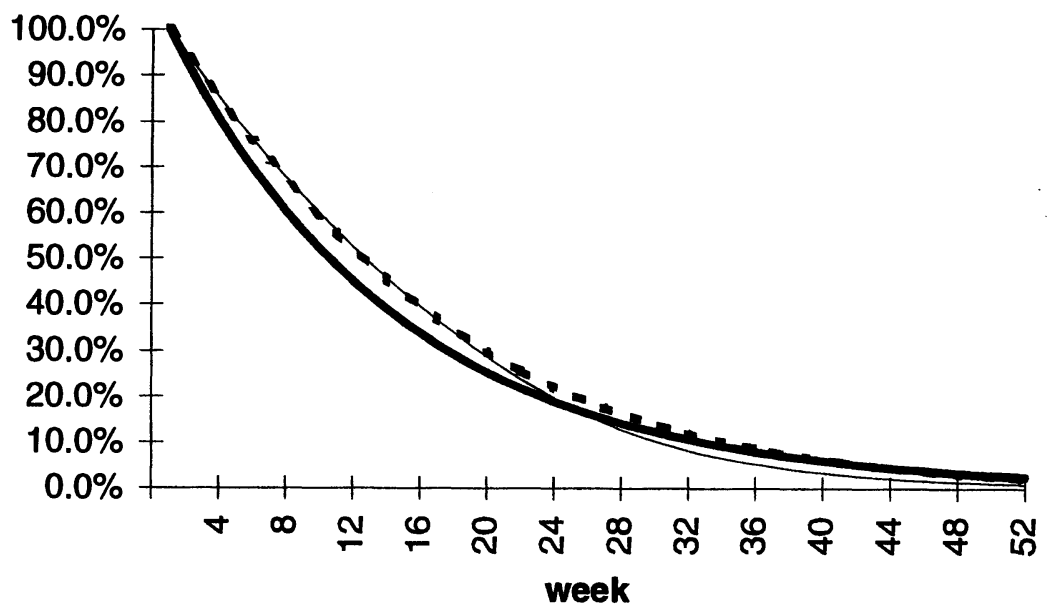

Opt. with tax Current - - Opt. no tax

Fig. 3.-Unemployment probabilities $(\sigma=1 / 2)$

In our computations we have assumed that the worker under consideration has no other source of income and thus consumes the income provided by the contract. Both the current system and the optimal one with no taxation provide insufficient consumption smoothing to the agent. In contrast, in the optimal contract the principal smooths the consumption of the agent by implicitly acting as a bank account. ${ }^{8}$

To evaluate the sensitivity of our results to the wealth position of the agent, we computed cost savings for agents endowed with different levels of initial assets, assuming that these assets earn the market interest rate. These assets allow the agent to partially substitute for the smoothing provided by the optimal contract. The calculations corresponding to the current system were modified accordingly to allow the agent to optimally choose to consume part of this endowment while unemployed to complement the unemployment benefits. For the optimal program we assumed that the assets provided a constant base consumption stream to the worker and the transfers from the principal added to (or subtracted from) this base consumption. Though this computation provides a lower bound to what can be achieved by a principal who can control the agent's savings, the

\footnotetext{
${ }^{8}$ This interpretation was suggested to us by Jean-Jacques Laffont.
} 
TABLE 2

Cost Savings and Initial Wealth

\begin{tabular}{llc}
\hline \hline Initial Wealth & \multicolumn{1}{c}{ Equivalent to } & Cost Savings (\%) \\
\hline 10,000 & 10\% of present value of wages & 5.5 \\
5,070 & 1 year of wages & 5.8 \\
1,292 & 1 quarter of wages & 11.6 \\
\hline
\end{tabular}

approximation should be quite good, particularly when the initial endowment of assets is high.

Table 2 gives the cost savings from switching to the optimal program for various levels of initial wealth. It can be readily seen that the savings are quite sensitive to this initial wealth. For an agent with wealth equivalent to one quarter of wages, the cost savings are only 11.6 percent compared to the 30 percent obtained for an agent with no wealth endowment. It can also be seen that at a wealth level of approximately one year of wages, the savings from the optimal contract are almost equivalent to those obtained when restricted to no taxation. Our results still suggest that when one is dealing with unemployed workers who have very limited access to outside borrowing and for whom the wage constitutes a large fraction of total income, the combination of higher initial replacement ratios with future taxation of earnings can offer substantial gains. On the other hand, if the agents have access to a credit market or the wage is not a very important part of their income, the additional gains from using the tax are more modest.

These considerations suggest an alternative insurance mechanism, which consists in providing the agent with a lump-sum transfer at the beginning of the unemployment spell, allowing the agent to smooth consumption and self-insure through savings of this endowment. The cost of this scheme is measured by the transfer that is needed to provide the agent with the same expected utility as under the current regime. The cost exceeds that of the current regime by more than 3 percent. This suggests that the insurance provided by the current regime has substantial value to the worker.

\section{Sensitivity Analysis}

In this subsection we consider how the results on cost savings given above change when some of the calibrated values are modified. Table 3 reports a summary of the results. The first three rows report the cost of the current contract (normalized to 100 for each case), the costs of the optimal without tax and the cost of the optimal with 
TABLE 3

Cost SAvings (\%)

\begin{tabular}{|c|c|c|c|c|c|}
\hline & \multirow[b]{2}{*}{$\begin{array}{c}\text { BENCHMARK } \\
\text { (1) }\end{array}$} & \multicolumn{2}{|c|}{$\begin{array}{l}\text { HAZARD } \\
\text { RATE }\end{array}$} & \multirow[b]{2}{*}{$e=u(w) / 3$} & \multirow[b]{2}{*}{$\begin{array}{c}\sigma=3 / 4 \\
(5)\end{array}$} \\
\hline & & $\begin{array}{l}15 \% \\
(2)\end{array}$ & $\begin{array}{l}20 \% \\
(3)\end{array}$ & & \\
\hline Cost of current system & 100.0 & 100.0 & 100.0 & 100.0 & 100.0 \\
\hline Minimum cost without tax & 92.8 & 94.5 & 92.2 & 89.9 & 74.8 \\
\hline Minimum cost with tax & 71.9 & 79.2 & 79.6 & 56.6 & 6.9 \\
\hline Equivalent lump sum & 103.2 & 100.7 & 96.8 & 89.7 & 105.1 \\
\hline
\end{tabular}

tax, as explained above. The last row reports the cost of the lumpsum scheme.

Column 1 reports the relative cost in each case for the benchmark parameter values, which have already been discussed. Columns 2 and 3 show the effects of increasing the calibrated value of the hazard rate, as suggested by the estimates in Meyer (1990). The percentage cost savings obtained for the Shavell-Weiss scheme remain basically unchanged, whereas the savings for the case with the tax are reduced from 30 percent to around 20 percent. The extra insurance provided by this optimal contract becomes less important as the unemployment risk is reduced. In contrast, the performance of the lump-sum scheme relative to the current regime improves as the hazard rate increases. This also reflects the reduced importance of the insurance provided by the current regime.

Column 4 reports results obtained assuming that there is a positive effort $e$ exerted by employed workers that is costly in terms of utility. This cost was set at one-third of the utility of consumption $u(w)$. The effort cost makes the return to working smaller from both the social and the private points of view and thus lowers the search effort. In order to keep the calibrated value of the hazard rate at the benchmark value of 10 percent, it was then necessary to increase parameter $r$, thus lowering the unemployment risk. Notice that the gains from the optimal contract are now even greater than in the benchmark case. The relative performance of the lump-sum scheme is also improved.

Finally, column 5 reports the costs when the risk aversion coefficient is raised to $3 / 4$. This makes both consumption smoothing and insurance more important for the agent. Note the dramatic reductions in the cost obtained by switching to the optimal contract. By providing more insurance and a smoother consumption profile, the principal can substantially reduce the expected discounted payment 


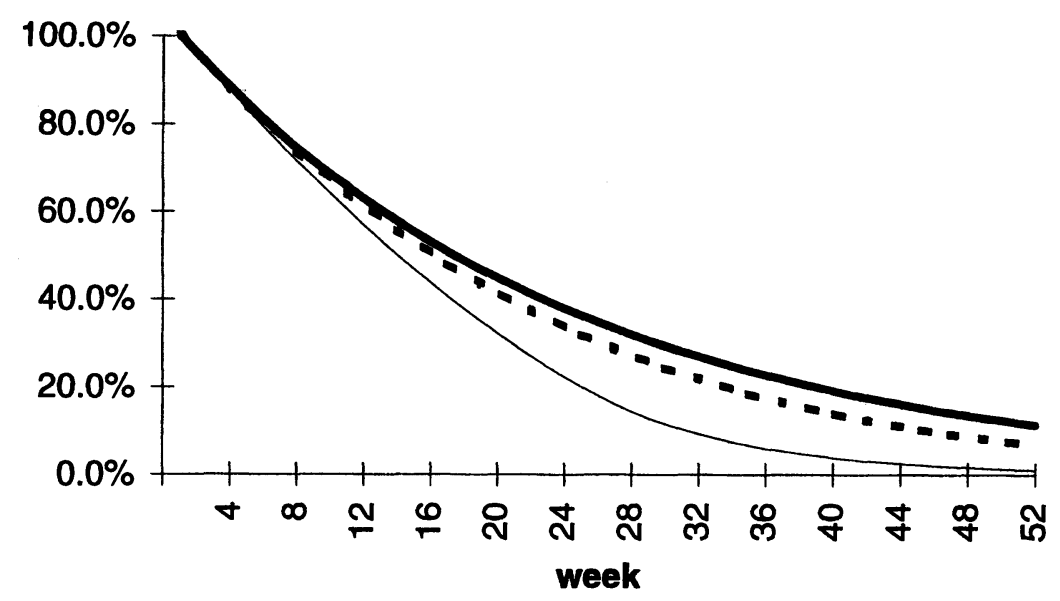

Opt. with tax Current - - Opt. no tax

FIG. 4.-Unemployment probabilities $(\sigma=3 / 4)$

to the agent. In contrast, the performance of the lump-sum payment scheme is reduced. This reflects again the increased importance of insurance.

The extra insurance provided by the optimal contracts can have the effect of reducing the incentives for job search. This effect is reported in figure 4 , which presents the unemployment probabilities when $\sigma=3 / 4$, for the current contract, the optimal without the tax, and the optimal with the tax. It is quite clear that for a worker with this degree of risk aversion, the optimal contract provides much lower incentives for reemployment than the current regime. Introducing the optimal unemployment contract could then imply an increase in the unemployment rate. The large gains derived from this contract are thus explained by its provision of better insurance and consumption smoothing.

\section{Final Remarks}

In this paper we considered the problem of optimal design of unemployment insurance when the search effort of the unemployed worker cannot be monitored by the enforcing agency. We established that in the optimal contract benefits decrease throughout the unemployment spell and that, once employed, the agent is levied a tax that increases with the length of the unemployment spell. By allowing this tax to be a function of the unemployment spell, we 
broaden the set of instruments that the contract considers, relative to the existing literature.

Our analytical results suggest that this extra degree of freedom is not redundant, allowing the contract to provide a smoother consumption profile to the agent. Our numerical results suggest that such an extension can be quantitatively important, significantly reducing the cost of the contract (or increasing the utility provided) for an agent who has limited wealth or access to alternative means to smooth consumption.

Gruber (1996) studies the role that the current unemployment insurance regime has in providing for smoother consumption. He finds that agents covered by unemployment insurance exhibit a substantially lower decrease in consumption when entering unemployment, but this difference disappears after reemployment or when benefits are exhausted. This evidence suggests the relevance of the consumption smoothing provided by an optimal contract.

The model considered is fairly specialized, and there are several dimensions in which it could be extended. In our model there is a single unemployment spell. A possible extension is to allow for multiple unemployment spells by introducing exogenous job terminations, thus creating a flow from employment to unemployment. In Hopenhayn and Nicolini (1996), we study that case, establishing that the analytical results derived here are still valid. The benefits provided decrease with the length of current and past unemployment spells, and similarly the tax on wages increases with the length of all past unemployment spells.

Wang and Williamson (1996) analyze a model of repeated unemployment spells with endogenous job termination, where a worker's effort affects not only the probability of finding a job but also the probability of keeping it. In contrast to the case of exogenous termination discussed above, in their model net transfers to the agent also depend on the duration of the period of employment. This is an interesting extension since in most unemployment insurance systems eligibility or coverage is affected by previous employment duration. ${ }^{9}$ Wang and Williamson's numerical results also confirm the large welfare gains that may be obtained by shifting to a better unemployment insurance system.

Another possible extension is to consider a model in which informational asymmetry arises from the imperfect monitoring of job offers received by the unemployed agent. It has been often argued

\footnotetext{
${ }^{9}$ In Hopenhayn and Nicolini (1996), we also obtain this form of employment dependence when job characteristics cannot be perfectly monitored by the principal.
} 
that unemployed workers are reluctant to accept job offers or delay the starting period of a new job while enjoying unemployment benefits. The type of contract suggested in this paper would punish the workers for such a delay, providing incentives for job acceptance. It can thus be conjectured that the results obtained here are likely to extend to a situation with adverse selection.

As in other models of repeated moral hazard, we have assumed that the principal controls directly the consumption of the agent. A feature that is common to all these models is that along the optimal contract the agent is savings-constrained: if the agent could save part of the transfer received without knowledge of the principal, he would choose to do so. This feature of the optimal contract is explained by the use of the dynamic profile for incentive purposes. If the principal cannot monitor the agent's savings, the Euler equation for the agent's optimal-savings problem becomes a constraint of the optimal design. As shown by Fudenberg, Holmstrom, and Milgrom (1990), this breaks the optimal design problem into a sequence of static problems: at each stage the principal provides the agent with an actuarially fair insurance contract for that specific period, and the probabilities associated with the different outcomes (unemployment/employment) are endogenous and obviously influenced by the contract.

A further complication arises in this case if the principal does not have all the relevant information to predict the optimal behavior of the agent. Such is the case if the principal could not monitor the agent's wealth, unless preferences are of the negative exponential type so that search decisions are independent of the agent's wealth. As pointed out by Fudenberg et al., the asymmetric information problem that arises in that case becomes very difficult to analyze. It may be conjectured that though agents are savings-constrained in the optimal contract, the cost of deviating from the optimal savings path can be quite high for the principal, and thus the associated Euler equation will not be severely violated. A benchmark computation could be obtained by analyzing the negative exponential case.

Our numerical results are already suggestive but can be substantially improved. The function relating effort to job offers plays an important role in our model and in our quantitative analysis. We impose very strong functional form restrictions by specifying this function to belong to a single parameter family of exponential distributions. The estimates of hazard rates obtained by Meyer (1990) provide substantial information that could be used to estimate a semiparametric specification of this search function. This would 
allow us to obtain more reliable estimates of the advantages of the optimal design.

\section{Appendix}

Lemma 1. The multiplier $\eta$ is positive.

Proof. Assume not. Then from (11) and (12) we obtain $C^{\prime}\left(V^{u}\right) \geq W^{\prime}\left(V^{e}\right)$. Then from (13) we obtain

$$
C^{\prime}\left(V^{u}\right) \geq C^{\prime}(V) \geq W^{\prime}\left(V^{e}\right),
$$

which together with the incentive-compatibility constraint imply

$$
V \leq V^{u}<V^{e} .
$$

Letting $c$ denote the constant consumption stream obtained if the agent becomes employed and $c^{u}$ current consumption and using (6) and (12), we obtain

$$
\frac{1}{U^{\prime}(c)}=\frac{1}{U^{\prime}\left(c^{u}\right)}+\eta \frac{p^{\prime}(a)}{p(a)}
$$

which implies $c^{u} \geq c$. Since $V^{e}=U(c) /(1-\beta)$, using (8) we obtain

$$
\left[U\left(c^{u}\right)-U(c)\right]-a+\beta[1-p(a)]\left(V^{u}-V^{e}\right)=V-V^{e},
$$

which can be written as

$$
\left[U\left(c^{u}\right)-U(c)\right]+\left[\beta p(a)\left(V^{e}-V^{u}\right)-a\right]=\left(V^{e}-V^{u}\right)(\beta-1)-\left(V^{u}-V\right) .
$$

From the previous result, the first term in brackets on the left-hand side is positive. Note that the second term is the part of the utility function of the agent that depends on the action, which, by the incentive-compatibility constraint, is maximized with respect to the action. By setting $a=0$, the agent can make this term equal to zero. Thus, if zero is feasible, the maximum cannot be lower than zero, which means that the left-hand side is nonnegative. However, from (A1) the right-hand side is negative. This contradiction completes the proof.

\section{Proof of Proposition 2}

Let $V_{t}^{u}$ be the promised utility the contract offers to the agent at $t-1$ for next period, contingent on unemployment. Similarly, let $V_{t}^{e}$ be the promised utility the contract offers to the agent at $t-1$ for next period, contingent on employment. Also, let $a_{t}$ be the action the contract specifies at $t$. Then from (13) we can write 


$$
C^{\prime}\left(V_{t-1}^{u}\right)=\left[1-p\left(a_{t-1}\right)\right] C^{\prime}\left(V_{t}^{u}\right)+p\left(a_{t-1}\right) W^{\prime}\left(V_{t}^{e}\right)
$$

for all $t>1$. By replacing this equation in (13) $T$ times, we obtain

$$
\begin{aligned}
C^{\prime}\left(V_{t-1}\right)= & \sum_{i=0}^{T-1}\left\{\prod_{j=0}^{i-1}\left[1-p\left(a_{t-1+j}\right)\right]\right\} p\left(a_{t-1+i}\right) W^{\prime}\left(V_{t+i}^{e}\right) \\
& +\prod_{j=0}^{T}\left[1-p\left(a_{t-1+j}\right)\right] C^{\prime}\left(V_{t+T}^{u}\right) .
\end{aligned}
$$

Now, assume, toward a contradiction of $a$, that $V_{t}^{e}=V^{e}$ for all $t$. Then from proposition 1 it follows that $V_{t}^{u}$ is a decreasing sequence. The incentive-compatibility constraint (9) then implies that $a_{t}$ is an increasing sequence, so $p\left(a_{t}\right)>p\left(a_{t+k}\right)$ for all $t$, all $k$ positive. Thus

$$
0<\prod_{j=0}^{T}\left[1-p\left(a_{t-1+j}\right)\right]<\left[1-p\left(a_{t-1}\right)\right]^{T} .
$$

So the first part of the second term on the right-hand side of (A2) goes to zero as $T$ goes to infinity. As $C^{\prime}\left(V_{t}^{u}\right)$ is positive and decreasing, it is bounded, which means that the second term on the right-hand side goes to zero as $T$ goes to infinity. Then we can write

$$
C^{\prime}(V)=\sum_{i=0}^{\infty}\left\{\prod_{j=0}^{i-1}\left[1-p\left(a_{t-1+j}\right)\right]\right\} p\left(a_{t-1+i}\right) W^{\prime}\left(V_{t+i}^{e}\right) .
$$

But as we assumed that $V_{t}^{e}=V^{e}$, we obtain $C^{\prime}(V)=W^{\prime}\left(V^{e}\right)$, which contradicts (14).

\section{Proof of Proposition 3}

Using (10)-(12), the incentive constraint (13), and some algebra, we get

$$
C\left(V^{u}\right)-W\left(V^{e}\right)=\left\{\frac{-p^{\prime \prime}(a)[1-p(a)] p(a)}{p^{\prime}(a)^{3}}\right\}\left[W^{\prime}\left(V^{e}\right)-C^{\prime}\left(V^{u}\right)\right] .
$$

Suppose toward a contradiction that $V^{e}$ increases between two time periods. From proposition 1 we know that if $C$ is convex, $V^{u}$ will decrease, implying that $a$ increases. As a consequence, the left-hand side of (A4) will decrease and $W^{\prime}\left(V^{e}\right)-C^{\prime}\left(V^{u}\right)$ will increase, thereby increasing the right-hand side. Since $W^{\prime}\left(V^{v}\right)>C^{\prime}\left(V^{u}\right)$, condition $a$ implies that the term in brackets will increase, contradicting the equality given by equation (A4). Now consider condition $b$. From first-order condition (12), an increase in $V^{e}$ would require an increase in the multiplier $\eta$. Equation (10) and the incentive constraint imply that

$$
C\left(V^{u}\right)-W\left(V^{e}\right)=\eta \frac{-p^{\prime \prime}(a)}{\beta p^{\prime}(a)^{2}}
$$


As the left-hand side decreases and $\eta$ increases and since $\eta>0$, condition $b$ implies that the right-hand side of the equation above increases, generating a contradiction.

\section{Proof of Proposition 4}

Let $\bar{C}(V)$ denote the expected discounted cost of the optimal contract after the current consumption transfer has been given to the agent. The problem solved by this contract is

$$
\bar{C}(V)=\min _{a, V^{e}, V^{u}}\left\{p(a) W\left(V^{e}\right)+[1-p(a)] C\left(V^{u}\right)\right\}
$$

subject to

$$
U(c)-a+\beta\left\{p(a) V^{e}+[1-p(a)] V^{u}\right\}=V
$$

and

$$
\beta p^{\prime}(a)\left(V^{e}-V^{u}\right)=1 .
$$

The optimal consumption transfer is determined by

$$
C(V)=\min _{c} c+\bar{C}[V-u(c)] .
$$

It can be established that convexity of function $C$ implies convexity of $\bar{C}$. Using constraints (A6) and (A7) to define implicit functions $a\left(V, V^{u}\right)$ and $V^{e}\left(V, V^{u}\right)$, we can restate the problem defined above as

$$
\bar{C}(V)=\min _{V^{u}}\left\{p\left(a\left(V, V^{u}\right)\right) W\left(V^{e}\left(V, V^{u}\right)\right)+\left[1-p\left(a\left(V, V^{u}\right)\right)\right] C\left(V^{u}\right)\right\}
$$

After lengthy calculations it can be shown that the function defined in the right-hand side is submodular in $\left(V, V^{u}\right)$, and thus $V^{u}$ is a decreasing function of $V$. Finally, using the convexity of $C$, one proves that $V-u(c)$ increases with $V$, thus completing the proof of the proposition.

\section{References}

Atkeson, Andrew, and Lucas, Robert E., Jr.. "On Efficient Distribution with Private Information.” Rev. Econ. Studies 59 (July 1992): 427-53.

- " "Efficiency and Equality in a Simple Model of Efficient Unemployment Insurance." J. Econ. Theory 66 (June 1995): 64-88.

Fudenberg, Drew; Holmstrom, Bengt; and Milgrom, Paul. "Short-Term Contracts and Long-Term Agency Relationships." J. Econ. Theory 51 (June 1990): 1-31.

Green, David A., and Riddell, W. Craig. "The Economic Effects of Unemployment Insurance in Canada: An Empirical Analysis of UI Disentitlement." J. Labor Econ. 11, no. 1, pt. 2 (January 1993): S96-S147.

Gruber, Jonathan. "The Consumption Smoothing Benefits of Unemployment Insurance." Manuscript. Cambridge: Massachusetts Inst. Tech., March 1996.

Hansen, Gary D., and Imrohoroglu, Ayse. "The Role of Unemployment 
Insurance in an Economy with Liquidity Constraints and Moral Hazard." J.P.E. 100 (February 1992): 118-42.

Hopenhayn, Hugo, and Nicolini, Juan Pablo. "Optimal Unemployment Insurance and Employment History.” Manuscript. Buenos Aires: Univ. Torcuato di Tella, May 1996.

Melguizo, A., and Lopez, T. "El gasto público en prestaciones por desempleo en los paises de la Europa comunitaria." Presupuesto y Gasto Público, no. 3 (1991), pp. 165-83.

Meyer, Bruce D. "Unemployment Insurance and Unemployment Spells." Econometrica 58 (July 1990): 757-82.

Phelan, Christopher, and Townsend, Robert M. "Computing Multi-period, Information-Constrained Optima.” Rev. Econ. Studies 58 (October 1991): 853-81.

Shavell, Steven, and Weiss, Laurence. "The Optimal Payment of Unemployment Insurance Benefits over Time." J.P.E. 87 (December 1979): 134762.

Spear, Stephen E., and Srivastava, Sanjay. “On Repeated Moral Hazard with Discounting." Rev. Econ. Studies 54 (October 1987): 599-617.

Usami, Yasuo. "Payroll-Tax Financed Unemployment Insurance with $\mathrm{Hu}-$ man Capital."' Ph.D. dissertation, Massachusetts Inst. Tech., May 1983.

Wang, Cheng, and Williamson, Stephen. "Unemployment Insurance with Moral Hazard in a Dynamic Economy." Carnegie-Rochester Conf. Ser. Public Policy 44 (June 1996): 1-41. 
http://www.jstor.org

\title{
LINKED CITATIONS
}

- Page 1 of 2 -

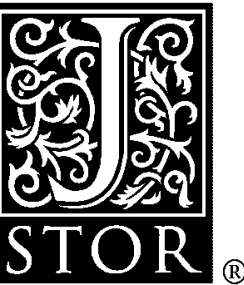

You have printed the following article:

\section{Optimal Unemployment Insurance}

Hugo A. Hopenhayn; Juan Pablo Nicolini

The Journal of Political Economy, Vol. 105, No. 2. (Apr., 1997), pp. 412-438.

Stable URL:

http://links.jstor.org/sici?sici=0022-3808\%28199704\%29105\%3A2\%3C412\%3AOUI\%3E2.0.CO\%3B2-H

This article references the following linked citations. If you are trying to access articles from an off-campus location, you may be required to first logon via your library web site to access JSTOR. Please visit your library's website or contact a librarian to learn about options for remote access to JSTOR.

\section{References}

\section{On Efficient Distribution with Private Information}

Andrew Atkeson; Robert E. Lucas, Jr

The Review of Economic Studies, Vol. 59, No. 3. (Jul., 1992), pp. 427-453.

Stable URL:

http://links.jstor.org/sici?sici=0034-6527\%28199207\%2959\%3A3\%3C427\%3AOEDWPI\%3E2.0.CO\%3B2-N

\author{
The Economic Effects of Unemployment Insurance in Canada: An Empirical Analysis of UI \\ Disentitlement \\ David A. Green; W. Craig Riddell \\ Journal of Labor Economics, Vol. 11, No. 1, Part 2: U.S. and Canadian Income Maintenance \\ Programs. (Jan., 1993), pp. S96-S147. \\ Stable URL: \\ http://links.jstor.org/sici?sici=0734-306X\%28199301\%2911\%3A1\%3CS96\%3ATEEOUI\%3E2.0.CO\%3B2-L
}

\section{Unemployment Insurance and Unemployment Spells}

Bruce D. Meyer

Econometrica, Vol. 58, No. 4. (Jul., 1990), pp. 757-782.

Stable URL:

http://links.jstor.org/sici?sici=0012-9682\%28199007\%2958\%3A4\%3C757\%3AUIAUS\%3E2.0.CO\%3B2-0 
http://www.jstor.org

\section{LINKED CITATIONS \\ - Page 2 of 2 -}

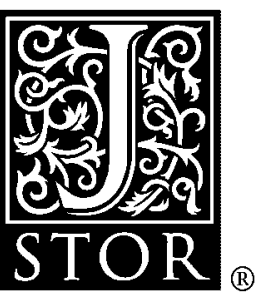

\section{Computing Multi-Period, Information-Constrained Optima}

Christopher Phelan; Robert M. Townsend

The Review of Economic Studies, Vol. 58, No. 5. (Oct., 1991), pp. 853-881.

Stable URL:

http://links.jstor.org/sici?sici=0034-6527\%28199110\%2958\%3A5\%3C853\%3ACMIO\%3E2.0.CO\%3B2-B

\section{On Repeated Moral Hazard with Discounting}

Stephen E. Spear; Sanjay Srivastava

The Review of Economic Studies, Vol. 54, No. 4. (Oct., 1987), pp. 599-617.

Stable URL:

http://links.jstor.org/sici?sici=0034-6527\%28198710\%2954\%3A4\%3C599\%3AORMHWD\%3E2.0.CO\%3B2-E 